\title{
DESIGNING THE APPROPRIATE DATA COLLECTION METHOD FOR PUBLIC TRANSPORT PASSENGER SATISFACTION ANALYSIS
}

\author{
Blawal Hussain ${ }^{1}$, Mohammad Maghrour Zefreh ${ }^{2}$, Adam Torok $^{3}$ \\ ${ }_{1,2,3}$ Budapest University of Technology and Economics, Department of Transport Technology and Economics, Hungary
}

Received 11 February 2018; accepted 27 March 2018

\begin{abstract}
Incessantly increasing urbanization is a threat to mobility, environment and ultimately to the quality of life. Promoting public transport in the major cities seems to be a promising solution to this issue which can be achieved by moving toward attracting more satisfied public transport passengers (PTP). The first step in PTP satisfaction analysis is collecting the reliable data which is equally suitable for all passenger groups (i.e. handicapped, visually impaired, etc.) in order to limelight the most important concerns of the public transport users. We assume that a satisfied customer would be willing to purchase the product again and will stay loyal to the provider as long as the gap between his perceived quality and expected quality is less. Among various methods of data collection, Customer satisfaction survey (CSS) suits best to know about the extent of users' satisfaction. In the current paper, at first, the relevant data collection methods have been reviewed and then a passenger satisfaction questionnaire has been designed which rates the extent of Budapest PTP satisfaction and dissatisfaction on a Likert chart. It should be underlined that different set of individual characteristics (age, gender, level of education, overall passenger health condition, etc.), as well as different service attributes (price, frequency, ease of boarding and alighting, etc.), are considered in the aforementioned questionnaire for further cluster analysis of the collected data.
\end{abstract}

Keywords: public transport passenger satisfaction, data collection, passenger characteristics, service attributes.

\section{Introduction}

This era of urbanization has led to major mobility problems all around the globe. The increasing rate of motorization is causing serious threats to environment and quality of life. Promoting the use of Public Transport is the only way out to keep our cities mobilized and more sustainable. In past few decades, urban areas across the world both in developed and developing countries have become automobile dominated and less sustainable resulting in environmental degradation, energy depletion, visual intrusion, accidents and congestion (Pojani and Stead, 2015). Public transport (PT) plays an important role in urban settings. Moreover, it may contribute to solving the congestion, mobility, $\mathrm{CO}_{2}$ emissions etc. problems in cities (Mouwen, 2015). The efficiency of transportation system plays an important role in stabilizing the economy and welfare of city's population. The main focus is currently placed not so much on the construction of new objects of transport infrastructure, but mostly on the efficient use of the existing ones.

${ }^{3}$ Corresponding author: torok.adam@mail.bme.hu 
Therefore, development of a high-quality urban public transport system that meets the requirements of tenants is a key concern of the city development (Pticina, 2011).

Sustainable urban transport is the solution to avoid all traffic born problems. The introduction of public policies that discourage the use of automobiles in growing cities can help to a greater extent in achieving the desired sustainability in the transportation sector. If we agree with (Pawlasova, 2015) that when inhabitants use PT vehicles instead of the private cars the environmental pollution is reduced, noise in the city is lowered and also tourists can appreciate cities and tourist centres with simple and customer friendly public transport, then this is the time to promote public transportation. One of the easiest ways of attracting more passengers to $\mathrm{PT}$ is looking at PT performance in the way the passengers look at. To this end, a passenger satisfaction analysis seems to be a promising solution in order to find the potential drawbacks and strengths of the current PT system from the passengers' standpoints.

The main aim of the current paper is, at first, to review the relevant data collection methods which might be suitable for PT satisfaction analysis and then to design a suitable data collection tool for PT satisfaction analysis in Budapest, Hungary. Keeping in view the regional, economic and cognitive disparities, this paper aims to devise a data collection tool which would be equally suitable for all public transport user groups i.e. locals, tourist, elderly, visually impaired, handicapped, etc.

\section{Customer Satisfaction}

In today's world of ever increasing and escalating competition, high service quality should be targeted to keep attracting new customers and making up to the loyalty of old ones. To survive and thrive in the competitive market, companies must need to know that up to what extent their customers are satisfied with the products. Customer satisfaction is, therefore, the difference between expected and actual quality of a product at the end of customer. Customer satisfaction, therefore, highlights and explains the link between what a company does (in terms of the products and services offered) and how its customers react. For public transport, this link is a key concern (Fellesson and Friman, 2008). Customer satisfaction is associated with the loyalty of the customers and we assume that the satisfied customer would be willing to buy the product again. Customer satisfaction is strongly influenced by customer expectations. The gap between perceived quality and expected quality, the so-called "expectancy disconfirmation" is a strong predictor of customer satisfaction (Oliver, 1980; Rust et al., 1995). When perceived services are lower than expected services the high degree of dissatisfaction of the customers can divert customers to the other service providers. Reduction in this discrepancy of perceived and expected quality can attain the loyalty and willingness of the customers to buy the product again.

\subsection{Public Transport Passenger Satisfaction}

Public transport network plays an important role in the efficient mobility of passengers in major cities. In order to make public transport competitive with other modes of transportation, especially with private cars, we need to know about travel's satisfaction. Undoubtedly travel's satisfaction varies largely depending on the socio-economic 
background of the residents of the same city but collecting data from passengers and analyzing it afterward can narrow down their most important needs. Knowing what makes travellers satisfied and what would motivate them to choose public transport over their own car is of vital importance. By knowing what would motivate actual/potential passengers, public transport organizations responsible for planning public transport can shift their focus to important areas which need improvement.

Public transport passenger satisfaction is influenced by a number of factors which not only varies from person to person but also by the demographic changes. According to (Oña et al., 2013) and (Antonucci et al., 2014), passenger satisfaction with public transport can be grouped into a number of latent variables consisting service organization, safety, and reliability, human resources and comfort, and cleanliness.

(Oña et al., 2013) found in their studies that service attributes including frequency, speed, punctuality and the provided information may have the influence on PT user's satisfaction very much. On the other hand, the other variables like comfort and personnel are of little importance for PT users. (Mouwen, 2015) in his research stipulated important drivers of customer satisfaction with public transport which includes service attributes such as punctuality, the speed of travel and frequency followed by driver behaviour and cleanliness of vehicle.

\section{Review of Data Collection Methods}

One of the major problems in the transport sector is the limitations of land use. Many cities in the world are already so packed up that new infrastructure could not be accommodated with the existing one. To ensure congestion-free mobility, the integration of urban public transport with the existing infrastructure and travellers' reliance on urban public transport is needed. Therefore development and innovations in the public transport sector are of key concern.

To evaluate the quality (or performance) of the urban public transport system, an appropriate data collection method is of great importance. According to (Brace, 2018), there are following data collection methods each with their own merits and demerits:

- Interviewer-administered interviews (face to face, computer-assisted personal interviewing (CAPI) and telephone administered interviews);

- Self-completion surveys (paper and web-based surveys).

Out of all above mentioned methods, the "Self-completion survey" is the most feasible and suitable as (Brace, 2018) also says it can be done in complete absence of the interviewer from the process and this way of collecting data also remove major source of potential bias in the responses and respondents tend to be honest about sensitive subjects.

In this regard, (Pticina, 2011) suggested customer satisfaction survey (CSS) suits best for customer satisfaction measurement. Customer satisfaction survey (CSS) is satisfaction measuring tool and it must be distinguished from performance measurement tool. In CSS, customer judges that to what extent provided services meet his/her requirements. 
For customer satisfaction survey CSS, a questionnaire is needed and according to (Brace, 2018) the first thing is "Defining the required information" followed by the sequencing, screening, and exclusion of unimportant question. Followings are the main types of attitudinal rating scales questionnaires (Brace, 2018):

- Likert scale;

- Semantic differential scale;

- Stapel scale.

Likert scale, considers fixed choice response formats in order to measure attitudes or opinions whereas, semantic differential scale mainly designed to measure the connotative meaning of objects, events, and concepts. Then these connotations will be used to derive the attitude towards the given object, event or concept. Stapel scale is a unipolar rating scale that has 10 categories ranging from -5 to +5 without any neutral point. This rating scale is mainly designed to measure the respondent's attitude towards one object.

\subsection{Considered Factors in Data Collection}

There are many subjective and objective factors directly affecting the passengers' satisfaction and few of them have a greater impact on satisfaction than others. A large-scale survey from London was done by (Verbich and El-Geneidy, 2016) to know about variation in satisfaction with bus transit service among riders with encumbrance and riders with disabilities. The main factors they considered were trip characteristics including bus stops/ shelter, bus condition, ride quality, and availability of information. (Verbich and El-Geneidy, 2016) further mentioned that service attributes mainly contain reliability, waiting time, total journey time, journey purpose and regularity of use.

According to (Imam, 2014), the most important factors to be considered for Jordan's public transport passengers includes reliability, convenience, safety, comfort, accessibility, and affordability. In his survey, (Imam, 2014) made the questionnaire for passengers satisfaction for public transports (Buses, mini buses, Jitneys, regular taxis) and got 376 responses. Based on the respondents' answers he carried ANOVA statistical test for prioritizing important factors. The ANOVA is a statistical test used to compare means of two or more samples to determine the heterogeneity of the means through an analysis of group variances (Sweis et al., 2013). For the passengers of Czech Republic, the service parameters (timetable clarity, station proximity, vehicle cleanliness, information, transport comfort, safety, transport speed, punctuality) and logistic parameters (frequency, fare, transport speed, service continuity punctuality) are important (Pawlasova, 2015). (Pawlasova, 2015) reached out to 592 respondents and used factor analysis/Varimax method to quantify the factors. In Finland's capital Helsinki the satisfaction factors include general cleanliness, seat comfort, accessibility and sense of safety (Vanhanen and Kurri, 2007). Table 1 gives a brief and quick overview of some of the studies done by various researchers in the various part of the world over the topic of "Satisfaction with public transport". In various part of the world, the data collection techniques and the questions to be asked by respondents differ heavily. Aim of this paper is to hit with the exact data collection tool and make respondents more concerned about what is important for them. 


\section{Table 1}

Summary of the Previous Studies on Satisfaction with Public Transportation

\begin{tabular}{|c|c|c|c|c|}
\hline Reference & Method & Factors & Sample size & PT mode \\
\hline $\begin{array}{l}\text { (Verbich and } \\
\text { El-Geneidy, } \\
2016)\end{array}$ & $\begin{array}{c}\text { Principle } \\
\text { component } \\
\text { analysis }\end{array}$ & $\begin{array}{l}\text { Bus stops, available information, ride quality, } \\
\text { regularity of use, reliability, journey time }\end{array}$ & 65,506 & Bus Transit \\
\hline (Imam, 2014) & ANOVA* & $\begin{array}{l}\text { Reliability, convenience, safety, comfort, } \\
\text { accessibility and affordability }\end{array}$ & 376 & $\begin{array}{c}\text { Bus, mini bus, } \\
\text { Jitney, Regular } \\
\text { Taxi }\end{array}$ \\
\hline $\begin{array}{l}\text { (Pawlasová, } \\
\text { 2015) }\end{array}$ & $\begin{array}{c}\text { Factor } \\
\text { analusis/ } \\
\text { Varimax/ } \\
\text { SEM }^{* *}\end{array}$ & $\begin{array}{l}\text { Service parameters (timetable clarity, station } \\
\text { proximity, vehicle cleanliness, Information, } \\
\text { transport comfort, safety, transport speed, } \\
\text { punctuality) and logistic parameters } \\
\text { (frequency, fare, transport speed, service } \\
\text { continuity punctuality) }\end{array}$ & 592 & $\begin{array}{l}\text { Overall public } \\
\text { transport of } \\
\text { Czech Republic }\end{array}$ \\
\hline $\begin{array}{c}\text { (Vanhanen and } \\
\text { Kurri, 2007) }\end{array}$ & $\mathrm{AHP}^{* * *}$ & $\begin{array}{l}\text { General cleanliness, seat comfort, accessibility } \\
\text { and sense of safety }\end{array}$ & 1,552 & Bus transit \\
\hline
\end{tabular}

\section{Suggested Data Collection Method}

Having a deep look over data collection techniques in combination with Hungarian education system, our opted technique should be designed in a way that respondents will find easy to answer as suggested by (Brace, 2018). Therefore, the 5 scale Likert scaling method has been applied to the designed questionnaire which would help in eliciting an easy and reliable choice from respondents.

The first part of the questionnaire with individual characteristics will help to know how these parameters help in making an efficient and "design for all" public transport system. The considered individual characteristics in the designed questionnaire are as follows:

- Type of passengers (Hungarian, International with either working or educational purpose and tourists);

- Age within the predefined intervals, gender and level of education separated in primary, secondary and university levels;
- The frequency of Public Transportation usage;

- Purpose of the trips made by Public Transportation;

- Overall health condition of the passengers including wheelchair, visually impaired, Elderly etc. passengers;

- Car ownership status.

It should be underlined that categorizing "health conditions" including pregnant, visually impaired, handicapped, etc. will include the perspective of individuals with some sort of disability as these people are part and parcel of the transportation system.

The second part of the questionnaire was dedicated to the service attributes in Budapest public transportation system which would cover both subjective and objective factors. The considered service attributes in the designed questionnaire are as follows:

- $\quad$ Price and departure frequency of Public Transportation in Budapest;

- Reliability of the Budapest Public Transportation schedule; 
- Closeness of Public Transportation stations to the daily origin-destinations of the passengers;

- Seating capacity of the Public Transportation vehicles;

- Cleanliness and temperature inside the Public Transportation vehicles;

- Ease of boarding and alighting from the Public Transportation vehicles;

- The behaviour of drivers, selling staffs, and on-board controllers;

- Safety and security at terminals and stops;

- Travel information quality before journey and on-board information on delays and service changes;

- Availability of time tables on-board.

At the end, these questions were ended up with the question of the overall satisfaction from Budapest public transportation. It should be highlighted that the questionnaire has been provided both in English and Hungarian language for the sake of attracting all passenger types (Hungarian, International, etc.).

\section{Conclusions}

In this rapid growth of urbanization cities are becoming more packed and less movable. Motorization is one of the major issues in congestion. Making public transport a priority is the only solution to this problem. This goal can be achieved by knowing the satisfaction of the public transport users. We assume that the satisfied customer would be willing to purchase our product (in our case using Public transport) again. Public transport passenger satisfaction is influenced by number of factors which not only varies from person to person but also by the demographic changes. Customer Satisfaction Survey (CSS) is the best possible way to know about the satisfaction level of passengers. Likert chart which is also called agreed-disagreed scale, suits best in knowing the extent of customer satisfaction or dissatisfaction. Likert chart includes both subjective and objective factors about passenger satisfaction. In this paper, at first, the available methods of data collection for PT passenger satisfaction analysis have been investigated and then an appropriate questionnaire has been designed for further data collection in the city of Budapest. The proposed questionnaire constitutes a variety individual characteristics as well as a range of service attributes for further cluster analysis. The considered rating scale in the proposed questionnaire is the Likert chart ranging from very unsatisfied (1) to very satisfied (5).

\section{Acknowledgement}

This work is supported by the ÚNKP-17-III New National Excellence Program of the Ministry of Human Capacities of Hungary.

\section{References}

Antonucci, L.; Crocetta, C.; d'Ovidio, F.D.; Toma, E. 2014. Passenger satisfaction: a multi-group analysis, Quality and Quantity 48(1): 337-345. https://doi. org/10.1007/s11135-012-9771-7

Brace, I., 2018. Questionnaire design: How to plan, structure and write survey material for effective market research. Kogan Page Publishers. 288 p.

de Oña, J.; de Oña, R.; Eboli L.; Mazzulla, G. 2013. Perceived service quality in bus transit service: A structural equation approach, Transport Policy 29: 219226. DOI:10.1016/ j.tranpol.2013.07.001.

Fellesson, M.; Friman, M. 2008. Perceived satisfaction with public transport service in nine European cities, Journal of the Transportation Research Forum 47(3): 93-103. 
Imam, R. 2014. Measuring Public Transport Satisfaction from User Surveys, International Journal of Business and Management 9(6): 106-114. DOI: http://dx.doi. org/10.5539/ijbm.v9n6p106.

Mouwen, A. 2015. Drivers of customer satisfaction with public transport services, Transportation Research Part A: Policy and Practice 78: 1-20. https://doi.org/10.1016/j. tra.2015.05.005.

Oliver, R.L. 1980. A cognitive model of the antecedents and consequences of satisfaction decisions, Journal of Marketing Research 17: 460-469. DOI: 10.2307/3150499.

Pawlasová, P. 2015. The factors influencing satisfaction with public city transport: A structural equation modelling approach, Journal of Competitiveness 7(4): 1832. http://dx.doi.org/10.7441/joc.2015.04.02.

Pojani, D.; Stead, D. 2015. Sustainable Urban Transport in the Developing World: Beyond Megacities, Sustainability 7(6): 7784-7805. https://doi.org/10.3390/ su7067784.

Pticina, I. 2011. The methodology of data collection about public transport service quality. In Proceedings of the 11th International Conference "Reliability and Statistics in Transportation and Communication" (RelStat'11), 19-22 October 2011, Riga, Latvia, 155-164.
Rust, R.T.; Zahorik, A.J.; Keiningham, T.L. 1995. Return on quality (ROQ): Making service quality financially accountable, The Journal of Marketing 59(2): 58-70. DOI: $10.2307 / 1252073$.

Sweis, G.J.; Imam, R.M.; Kassab, G.M.; Sweis, R. 2013. Customer satisfaction in apartment buildings: the case of Jordan, Life Science Journal 10(12s): 237-245.

Vanhanen, K.; Kurri, J. 2007. Quality Factors in Public Transport. Report of the Transport Research ProgrammeJOTU. WSP LT Consultant Ltd. and the Finish Local Transport Association, Finland. 7 p.

Verbich, D.; El-Geneidy, A. 2016. The pursuit of satisfaction: Variation in satisfaction with bus transit service among riders with encumbrances and riders with disabilities using a large-scale survey from London, UK, Transport Policy 47: 64-71. https://doi.org/10.1016/j. tranpol.2015.12.009. 